the thumb, while the fingers introduced beneath the clavicle were pulling it outwards, and elevating it, the shoulder being kept back at the same time with the other hand. Reduction was easily accomplished in all these cases, and in a few days the men were able to work.

\section{FRACTURED CLAVICLE.}

I saw, in one of the late numbers of THE Lancer, an account of an apparatus for fractured clavicle. The more simple and the more ready at hand all these things are, the better; and I have for years treated this accident in the following manner:Elevate the shoulder of the affected side by putting the hand under the elbow, then take a handkerchief, doubled, and pass it under the elbow; tie it over the opposite shoulder as tight as you can; apply an adhesive plaster on a dossil of lint over the fracture, suspending the hand by another handkerchief around the neck. The clavicle is in apposition as soon as the shoulder is elevated, and the handkerchief is kept from slipping, either before or behind the elbow, by stitching it through in both places. This is to be worn for three weeks, and replaced occasionally; the only thing complained of is the pressure on the opposite shoulder, which may want a little soft wadding under the kerchief.

January, 1845.

\section{TURNING EFFECTED WITHOUT THE INTRODUCTION OF THE} ENTIRE HAND.

By WM. DAuton, M.R.C.S.E. Cheltenham.

I was requested by a neighbouring practitioner to accompany him to a case of preternatural presentation in a woman who had borne one or more children. I was informed that the liquor amnii had escaped some time, and that the bladder had been previously evacuated.

On making an examination, I found the right hand of the child protruding beyond the os externum, the shoulder resting upon the perinæum, and the spine (the os uteri being fully dilated) towards the abdomen. During an interval of relaxation, attempted a further introduction of my hand, but after a little time was obliged to desist, owing to the contractions of the uterus, which were very energetic, and followed each other in quick succession. A draught, containing forty drops of laudanum, was administered, and shortly after (not having removed my hand from the vagina) I made another gentle and steady effort to reach the feet of the child, but in this, too, I failed, owing to the continuance of the same cause. Anodyne draught ordered to be repeated.

The pains continuing with the same frequency and intensity, and the opiates having failed in making an impression on the system, I directed the patient to be bled from the arm, and immediately after the operation another opiate, of the same strength as the former, to be given. After a little time I again endeavoured to pass my hand, but this attempt was attended also with the same result; for when I moved my hand a little beyond the point at which $I$ had previously arrived, it was forced back by the expulsive action of the uterus.

Being unable to turn the child according to the method I invariably pursued, which was in accordance with that laid down by all systematic writers, and finding that no beneficial effect had been produced by the combined action of venesection and administration of laudanum, (120 drops of which, as will be seen, had been given within the short space of half an hour, ) and feeling, too, a reluctance in eviscerating the thorax, which should be a dernier resource-I determined, before I removed my hand, to try a plan, which, as far as I am aware, is original, and which then and there suggested itself to my mind.

I shall now endeavour, with as much perspicuity as I can, to describe the modus operandi of my plan. The case being one of extreme emergency, and one in which delay might be productive of disastrous consequences to the mother, I proceeded as follows:-

I passed the index and middle fingers of the right hand to the occinital protuberance of the child, and found I could raise the head upwards, and towards the left iliac fossa, in which position I succeeded in maintaining it during a pain, the subsidence of which gave me an opportunity of introducing the index finger of the left hand, which, resting against the lower cervical or upper dorsal vertebræ, served to prevent the child receding, as well as to form a kind of fulcrum by which the evolution of the child was further facilitated. I now pushed the head of the child still higher with the fingers of the right hand, whilst with that of the left I afforded firm support to the trunk during the pains, and during the remissions I passed successive portions of the spinal column towards the left ilium of the mother, whose position (being on the left side, as usual) favoured the operation in aiding the descent of the child by its own gravity to the left ilium, until I thereby caused the breech to present, which was immediately followed by contraction of the uterus, and expulsion of the child. The placenta speedily followed, and the woman recovered without a bad symptom. It would be right to add that it was a seven-months' child, and that it presented slight appearances of incipient decomposition.

I do not offer this case as one which carries with it any intrinsic value, but $I$ am under the impression that the adoption of the method of turning I suggest might, in some cases, supersede the introduction of the hand and arm, even at the completion of utero-gestation, and serve, in a great measure, to diminish the danger and suffering of the mother, as well as afford a better chance of existence to the child.

During a practice of nearly fifteen years in this county, I have met with six cases of arm-presentation in addition to the above. In four, I did not see the patients until some hours had elapsed after the waters had passed off; in these cases the children were dead. I effected delivery by bringing down the feet.

In two cases, I ruptured the membranes (the os uteri being fully dilated at the time) and brought down the feet. The children were born alive.

'The mothers recovered in all the above cases, and have since borne living children.

Feb. 10th, 1845 .

\section{THE HYDRATED PEROXIDE OF IRON IN POISONING BY} ARSENIC.

By W. Aluison, Esq. East Retford.

Aвout half-past five P.M., Dec. 2nd, 1844, I was desired to visit M. J- aged thirteen, residing three miles off, a girl of violent temper, who, having been severely reproved by her father on account of misconduct, had swallowed arsenic. Before four o'clock, a large teaspoonful, and before five o'clock, about the same quantity, was taken, each dose mixed in water; and she had suffered violent spasmodic pain, according to the messenger's (her brother's) account, "writhing," "twisting about," " moaning," and " making strange faces." On arriving at the house with a stomach-pump, castor oil, magnesia, and hydrated peroxide of iron, she was found vomiting, and more free from pain, but complaining of a sensation of burning heat in the throat and stomach, with a feeble pulse and a cold skin. After a little resistance on her part, and after having both coaxed her to swallow a heaped tablespoonful of the iron mixed in water, and threatened to overpower her and to use the stomach-pump, the iron was swallowed. About ten minutes afterwards, when thin gruel containing the magnesia was just cool enough to inject into the stomach, effectual vomiting occurred. A second quantity of iron was swallowed, and on my going up stairs a second time with the liquid for injecting, free vomiting again led to the administration of a similar dose of iron: about ten drachms had been then swallowed. After waiting half an hour, the girl drank an ounce of castor oil, which soon returned with a part of the iron.

Dec. 3rd.--Several motions, evidently containing the preparation of iron.

4th.- No motion during the night; pulse more natural ; pains slight. The opening mixture was repeated.

10th.-Recovering; aperients necessary, and she begged for pills. Blue pill, and compound extract of colocynth.

A question naturally arises-" Did the girl actually swallow the specified quantity of arsenic?"

No one saw her drink it; but the parents told me that they had no doubt about it. The father said her temper would lead her to any length. The mother found a mug with some milky liquid at the bottom, in which she had no doubt the girl had mixed arsenic, from a packet labelled, "Arsenic, Poison," which had been procured for the purpose of mixing amongst seed-wheat. The arsenic had been taken from a hole made through the paper, and was not to be found. The girl did not say what she had done, until she confessed to a favourite brother at the time when she was in violent pain, at half-past four o'clock. The girl was but thirteen, and was unlikely to know the effects of arsenic, which she described,-burning pain in the throat and stomach; the pain at times much more violent, \&c. To-day (Jan. 28, 1845) I met with her, and in conversation begged, for my own instruction, she would tell me whether or not she really did swallow arsenic, and what quantity, as I wanted to know how much might be swallowed without producing death; to which she unhesitatingly replied, " To the best of my knowledge, I really did swallow, at twice, altogether, more than half a tablespoonful, expecting it would very soon kill me." I once related a case (LANCET, vol. i. 1836・37, page 401) in which a girl was seen drinking thirty grains of the red nitric oxide of mercury, from which she recovered, as I thought, from the use of the stomach-pump.

The evidence and symptoms are tolerably conclusive that 